\title{
L'experiència alemanya de Manuel de Montoliu (1908-1911)
}

Xavier Fleck

fleck_xavier@hotmail.com

Universitat de Barcelona

Facultat d'Història

Departament d'Història i Arqueologia

Carrer de Montalegre, 6

08001 Barcelona

Resum: Amb l'arribada de Prat de la Riba a la Presidència de la Diputació de Barcelona l'any 1907 i la creació per part del Govern del Regne d'Espanya de la Junta de Ampliación de Estudios l'any 1908, començà l'enviament de desenes d'estudiants catalans fora de les fronteres espanyoles becats per les diferents administracions. El filòleg Manuel de Montoliu fou beneficiari d'una beca de la Diputació de Barcelona i de l'Institut d'Estudis Catalans per anar a estudiar filologia romànica a la Universitat de Halle an der Saale, a l'Imperi alemany. En aquest article es detalla com el filòleg obtingué la pensió per anar estudiar al Deutsches Kaiserreich i les seves experiències a Halle entre els anys I908 i i9II. A més a més, cal tenir en compte que Montoliu escrigué articles a diferents mitjans de comunicació catalans, com el diari catalanista republicà El Poble Català, on descrivia, entre moltes altres coses, el funcionament universitari alemany, convertint-se en un dels cronistes catalans més destacats al Segon Reich entre els anys I909 i I9IO. Això és destacat perquè donava a conèixer altres realitats acadèmiques fora del Regne d'Espanya a l'opinió pública catalana, la qual estava experimentant uns enormes canvis polítics, socials i culturals durant els últims anys del segle XIx i principis del segle Xx. També cal tenir en compte que Montoliu, com molts dels pensionats que viatjaren a l'estranger, acabà tenint càrrecs d'importància dintre de la Diputació de Barcelona i després la futura Mancomunitat de Catalunya a partir del I9I4.

Paraules clau: Manuel de Montoliu, catalanisme, germanofília, història cultural.

FLECK, Xavier, «L'experiència alemanya de Manuel de Montoliu (1908-1911)». Cercles. Revista d'Història Cultural, 24, 79-122. ISSN: 1139-0158. ISSN-e: 1699-7468. DOI: 10.1344/cercles2021. 24.1003. Data de recepció: 12/4/2021. Data d'acceptació: 13/6/2021. 


\section{Manuel de Montoliu's german experience (1908-1911)}

Abstract: The arrival of Prat de la Riba to the presidency of the Barcelona Provincial Council in 1907, and the creation of the Junta para Ampliación de Estudios by the Government of the Kingdom of Spain in 1908, allowed dozens of Catalan students to travel outside Spanish borders to study, funded by different governmental administrations. Philologist Manuel de Montoliu received a scholarship from the Barcelona Council and the Institut d'Estudis Catalans to study Romance Philology at the University of Halle an der Saale, in the German Empire. This article details how Montoliu obtained his scholarship to study in the Deutsches Kaiserreich, and his experiences in Halle from 1908 to I9II. Montoliu also wrote articles for various Catalan publications, such as the Republican Catalanist newspaper El Poble Català, where he described, among many other things, the German university system. Indeed, he became one of the most prominent Catalan chroniclers in the Second Reich between 1909 and 1910. This is important, because it informed Catalan public opinion, which was undergoing enormous political, social and cultural changes during the final years of the I9th century and the beginning of the 2oth century, as it became aware of other academic realities outside the Kingdom of Spain. Significantly, Montoliu, like many who were funded to travel abroad, would end up holding important positions within the Barcelona Council and then with the Commonwealth of Catalonia from I9I4 onwards.

KEYwORDs: Manuel de Montoliu, catalanism, germanophile, cultural history.

\section{Marc històric: el fin de siècle català i els pensionats a l'estranger}

Si parlem del món cultural i ideològic europeu dels últims anys del segle XIx fins al I9I4 és imprescindible parlar de la crisi del fin de siècle, és a dir, la consciència d'un canvi de segle (en aquest cas, del XIX al $\mathrm{xx}$ ) també suposa un canvi de paradigma. L'Europa d'aquell període estava ideològicament dominada per una gran admiració pels grans avenços socials, tecnològics, científics, etc. que s'anaven produint en

Cercles. Revista d'Història Cultural, 24 (2021), 79-122.

ISSN: 1139-0158. e-ISSN: 1699-7468. DOI: 10.1344/cercles2021.24.1003. 
aquell moment. Però, al mateix temps, existia un sector polític i cultural, força minoritari, conscient dels enormes canvis que s'havien produït en aquelles dècades, que pregonava que la mentalitat positivista del segle XIX havia portat la civilització europea a la decadència i que per tant s'havien de buscar nous models per fer-la ressorgir. ${ }^{\mathrm{I}}$

La Catalunya de la Segona Restauració no fou aliena al debat del fin de siècle, ja que, durant el període de la Belle Époque, fou testimoni de grans canvis polítics, socials i culturals. Cal remarcar que una de les característiques més destacades del fin de siècle català és que els intel.lectuals no només estaven preocupats pels conflictes socials i polítics i per les noves dinàmiques culturals sinó que, a més a més, assaltaren gradualment les estructures de poder institucional per poder millorar-ne el funcionament. Fou el catalanisme polític de finals del segle XIX i principis del segle XX un dels moviments que més bé representà les ambicions modernitzadores dels intel.lectuals del Principat. Per aconseguir els seus objectius polítics, els intel.lectuals buscaren altres referents fora del Regne d'Espanya per ser aplicats Catalunya.

Quan Enric Prat de la Riba aconseguí la Presidència de la Diputació de Barcelona, la seva administració començà a finançar pensionats que anessin a l'estranger a estudiar altres sistemes culturals i acadèmics fora del Regne d'Espanya per poder aplicar les millors propostes a Catalunya. Molts d'aquests becats eren, o serien, figures destacades del món cultural català. Fou en aquest context quan Montoliu va ser pensionat per la Diputació de Barcelona per anar a estudiar filologia romànica a la Universitat de Halle. Manuel de Montoliu no és una de les figures més conegudes del panorama intel.lectual català dels primers anys del segle xx, però el seu viatge al Kaiserreich no tan sols és un exemple per entendre les dificultats que tingueren tant els pensionats com la mateixa Diputació de Barcelona en la gestió

I Maximiliano Fuentes Codera, "Un viaje por los extremos. Eugeni d'Ors entre la Gran Guerra y el Fascismo (I9I4-I923)", Girona, Universitat de Girona, 2OII, pp. 2I-22. 
d'aquestes estades, sinó que també ajuda a comprendre com aquestes estades dinamitzaren del debat intel.lectual català. En el cas de Montoliu, les seves observacions sobre el sistema universitari a l'Imperi alemany van tenir influència en el mogut debat acadèmic de la Catalunya d'abans del i9i4.

\section{L'escassa bibliografia sobre l'estada de Manuel de Montoliu al Kaiserreich}

Historiogràficament, la contribució del filòleg Manuel de Montoliu sobre la visió de l'Alemanya per part del món intel.lectual català s'ha focalitzat essencialment durant el període de la Primera Guerra Mundial. Durant l'enorme debat públic que hi hagué a Catalunya i a la resta del Regne d'Espanya durant els anys que es produí la Gran Guerra, Montoliu fou un gran defensor de les Potències Centrals, especialment de l'Imperi alemany. Montoliu ha sigut mencionat en diverses publicacions que han tractat el debat intel.lectual català i espanyol durant la Gran Guerra. Els escrits més destacats són Francófilos y germanófilos: los españoles en la guerra europea, publicat l'any 1972 i escrit per Fernando Díaz-Plaja, ${ }^{2}$ Notícies d'abans d'ahir. Llengua $i$ cultura catalanes al segle $X X$, publicat l'any $201 \mathrm{i}$ i escrit per August Rafanell, ${ }^{3}$ i Germanófilos y neutralistas: proyectos tradicionalistas y regeracionistas para España (I9I4-I9I8), publicat l'any 2013 a la revista Ayer i escrit per Maximiliano Fuentes Codera. ${ }^{4}$

2 Fernando Díaz-Plaja, Francófilos y germanófilos: los españoles en la guerra europea», Barcelona, Dopesa, 1972, pp. 682-686.

3 August Rafanell, Notícies d'abans d'ahir. Llengua i cultura catalanes al segle XX, Barcelona, Acontravent, 20II, pp. 245-28I.

4 Maximiliano Fuentes CODERA, «Germanófilos y neutralistas: proyectos tradicionalistas y regeracionistas para España (I9I4-I9I8)», Fuentes Codera, Maximiliano (ed.); "La Gran Guerra en los intelectuales: España en Europa»; revista Ayer, núm. 91; 2013, pp. 63-92.

Cercles. Revista d'Història Cultural, 24 (2021), 79-122.

ISSN: 1139-0158. e-ISSN: 1699-7468. DOI: 10.1344/cercles2021.24.1003. 
El filòleg tarragoní va viure becat per la Diputació de Barcelona a l'Imperi alemany entre els anys 1908 i i9II. Durant el temps que va estudiar a la ciutat de Halle, juntament amb D'Ors, Montoliu fou un dels principals cronistes catalans sobre l'Alemanya guillermina. Des de l'any 1904 fins al 1908 havia publicat cròniques literàries a El Poble Català, moltes de les quals tractaven temes relacionats amb la cultura germànica. Un cop tornat a Catalunya l'any I9II continuà publicant articles que tractaven diversos aspectes de l'Imperi alemany.

A diferència d'altres intellectuals que contribuïren al debat germanòfil a Catalunya abans de la Gran Guerra, Montoliu ha sigut una figura escassament tractada. 'L'any 1997 es publicà una tesi doctoral titulada " "La Cataluña"; ideologia i poder a la Catalunya noucentista I907-I9I4", feta per Antoni Guirao, sobre la revista noucentista La Cataluña. Pel que fa a la figura de Manuel de Montoliu, l'autor contraposà els articles del filòleg tarragoní que es publicaren a La Cataluña amb els de Miquel Vidal i Guardiola, un economista d'idees proteccionistes que fou pensionat per estudiar a la Universitat Humboldt de Berlín. ${ }^{6}$ Una altra de les poques referències acadèmiques sobre l'estada del filòleg tarragoní a l'Alemanya guillermina ha sigut el llibre Pere Barnils: l'home, el lingüista i el mestre, escrit per Joan Julià Muné i publicat l'any 2000. Aquest volum conté la bibliografia del filòleg Pere Barnils, el qual, juntament amb Antoni Griera, fou company d'estudis de Manuel de Montoliu durant la seva estada a Halle. Julià Muné dedicà disset pàgines a l'estada que Barnils va fer a la Universitat de Halle entre els anys 1908 i 1912. Tot i que hi té un protagonisme menor, és interessant veure com aquest llibre és un dels pocs documents acadèmics que menciona l'experiència personal de Montoliu durant la

5 Rovira Soriano, Jordi; "Any Montoliu»; La Vanguardia Tarragona (I4/I/2OII); p. 4 [Suplement de La Vanguardia, any CXXX, núm. 46.43I, I4/I/20II].

6 Antoni Guirao, "La Cataluña»; ideologia i poder a la Catalunya noucentista 1907I9I4, Barcelona, Universitat de Barcelona; 1997, pp. 579-597. 
seva estada al Kaiserreich entre els anys I908 i I9II. ${ }^{7}$ Un altre document que menciona l'estada de Montoliu a l'Imperi alemany, tot i que molt menys, és el curt escrit de Fèlix Villagrassa titulat «Mancomunitat i ciència: La modernització de la cultura catalana», publicat l'any 2015. Cal destacar que l'escrit de Villagrassa és important perquè hi ha un dels llistats més extensos dels pensionats catalans que viatjaren fora del regne d'Espanya durant els primers anys del segle $\mathrm{xx} .^{8}$

\section{La biografia de Manuel de Montoliu abans de viatjar a I'Imperi alemany (1877-1908)}

Manuel de Montoliu i de Togodes, nascut a Barcelona el 30 d'abril de l'any I877, provenia d'una importat família aristocràtica del Camp de Tarragona. El seu pare, Plàcid-Maria de Montoliu i de Sarriera, arribà a ser alcalde de Tarragona entre els anys I865 i I867 i, en temps de la Restauració Borbònica, fou membre del Partit Conservador: va ser diputat pel districte de Tarragona entre els anys I876 i I88I i senador entre I884 i I885. Durant els seus primers anys de vida, Manuel de Montoliu estudià el batxillerat amb els jesuïtes de Manresa. L'any I896 es llicencià en Filosofia i Lletres i l'any 1903 es doctorà a Madrid. ${ }^{9}$ A partir de l'any I898 començà a col.laborar en revistes literàries com L'Avenç, Pèl i Ploma i Juventut. ${ }^{\mathrm{I}}$

Els anys d'estudiant de Manuel de Montoliu estan poc investigats, però a partir de les publicacions fetes en aquest període se sap que estava vinculat amb el moviment modernista i amb el catalanis-

7 Joan Julià Muné, Pere Barnils: l'home, el lingüista i el mestre, Barcelona, Abadia de Montserrat, 2000, pp. 18-35.

8 Fèlix Villagrasa Hernández, Mancomunitat i ciència: La modernització de la cultura catalana, Barcelona, Afers, 20I5, pp. 2I-28.

9 Jordi Rovira Soriano, «Any Montoliu»..., p. 4.

io Joan Julià Muné, Pere Barnils..., p. 23. 
me. Una de les descripcions més detallades sobre el Manuel de Montoliu d'aquells anys fou feta per l'escriptor i poeta Josep Maria de Sagarra en el seu llibre titulat Memòries, publicat l'any I954. Sagarra, el qual era parent llunyà de la família Montoliu, considerava que el filòleg tarragoní havia sigut el "primer home de lletres amb qui vaig tenir contacte i que en certa part colllaborà en les meves produccions inicials ${ }^{\text {"I }}$ quan tenia entre set i vuit anys. El Montoliu de finals del segle xIx i principis del segle xx, Sagarra el descriu com un individu atípic dintre dels ambients aristòcrates catalans de l'època:

Aleshores Montoliu era un xicot de vint-i-dos o vint-i-tres anys, i entre les ràncies famílies de Barcelona amb les quals estava emparentat tenia fama, com tots els seus germans, de bellesa física i de positiu talent; però era considerat com un revolucionari, un modernista i un catalanista, coses que entre les consciències emmidonades de l'època no eren precisament massa recomanables. ${ }^{\mathrm{I}}$

Però el que més destaca Sagarra de Montoliu és la seva producció com a literat i com a traductor de publicacions vinculades al món modernista:

Montoliu acabava de publicar un llibre de versos i una traducció de la Vita Nuova de Dant. Respirava l'atmosfera de L'Avenç i el de Pèl i Ploma i fins donava lliçons a una criatura com jo [...]. Montoliu, amb altres exaltats del modernisme $\mathrm{i}$ en unes golfes que tenia davant de la catedral el pintor Alexandre de Riquer, llegia i cimentava la Divina Comèdia i s'emborratxava materialment de Burne Jones, de Dante Gabriel Rosetti i de tot el pre-rafaelisme, que, en aquella època, representava el plat més exquisit. ${ }^{13}$

II Josep Maria de SAgarra, Memòries, Barcelona, Edicions 62, 20I2, p. 345.

I2 Ídem, pp. 345-346.

I3 Ídem, p. 346. 
Un cop doctorat, Montoliu es casà amb la violinista Júlia Vidal i, fins a l'any 1908, compaginà la feina d'administratiu de la Compañía de Tabacos de Filipinas amb la de crític literari. A partir de l'any 1904 començà a treballar a la secció literària del setmanari catalanista progressista El Poble Català. ${ }^{14}$ Quan l'any 1906 El Poble Català es convertí en diari, Manuel de Montoliu escrigué setmanalment en una secció titulada "Lletres catalanes», la qual durà fins a finals de l'any 1908..$^{\text {I5 }}$

\section{Enviament de pensionats: a la recerca d'un model universitari català}

La victòria de la coalició catalanista Solidaritat Catalana a les eleccions provincials del març de l'any 1907 provocà l'arribada d'Enric Prat de la Riba i Sarrà a la Presidència de la Diputació de Barcelona. Es tracta de la primera vegada que una de les institucions més destacades de Catalunya era governada per un president no vinculat als partits dinàstics, fet que no es produïa des del naixement de la Restauració borbònica a la dècada de $1870 .{ }^{16}$ Des del 1907 fins a la seva mort l'any 1917, Prat de la Riba va prioritzar la dinamització d'una potent política cultural. Des de finals del segle XIX, a Catalunya hi havia un gran moviment cultural que afectà diverses institucions del territori, com va ser el cas de l'Ateneu Barcelonès. ${ }^{17}$ La conflictivitat política i social del Regne d'Espanya a partir de l'any i898, l'aparició del catalanisme polític entre els anys I899 i I90 i el dinamisme cultu-

I4 Joan Julià Muné, Pere Barnils..., p. 23.

I5 Jordi Rovira Soriano, «Any Montoliu»..., p. 4.

i6 Albert Balcells, Enric Pujol, Jordi Sabater, La Mancomunitat de Catalunya $i$ l'autonomia, Barcelona, Proa, 1996, p. 46.

17 Jordi Casassas YMbert, Entre Escilla i Caribdis. El catalanisme i la Catalunya conservadora de la segona meitat del segle XIX, Barcelona, La Magrana, I990, pp. I2O-I2I.

Cercles. Revista d'Història Cultural, 24 (2021), 79-122.

ISSN: 1139-0158. e-ISSN: 1699-7468. DOI: 10.1344/cercles2021.24.1003. 
ral havien provocat l'augment d'una demanda més gran per regenerar la política cultural de les institucions. ${ }^{18}$

La necessitat de regeneració també era una reivindicació destacada en el món universitari català. Per exemple, durant els últims anys del segle xIx i principis del xx, el Govern espanyol tenia el control absolut de la Universitat de Barcelona pel que fa al professorat, als pressupostos i als programes d'estudi. ${ }^{19}$ Des de finals dels segle XIX hi hagueren veus que reivindicaren la necessitat de crear una entitat universitària que donés resposta a les necessitats intellectuals catalanes. En una intervenció feta a l'Ateneu Barcelonès l'any I898, l'arquitecte Lluís Domènech i Muntaner havia fet un discurs en què reivindicava la necessitat de crear una universitat que no depengués del Govern central:

És menester fer autònoma la universitat de Catalunya: que s'organitzi més àmplia i pràctica, disposant d'allò que l'estat hi destina ara i d'allò que Catalunya, mestressa dels seus recursos, té l'obligació d'afegir-hi. Cal que es triii $\mathrm{i}$ es formi el seu professorat i els seus directors amb els procediments que li sembli. Que cridi cada any a les seves càtedres algunes de les grans capacitats estrangeres per donar-hi cursos curts i pràctics de les especialitats i dels descobriments, experiències i operacions novament fetes. ${ }^{20}$

Un cop entrat el segle xx, el Govern espanyol era reticent a acceptar la investigació i la divulgació superior de la cultura catalana en la llengua pròpia. Per aquest motiu, se celebrà el Primer Congrés

I8 Albert BalCELls, Els Estudis Universitaris Catalans (1903-1985): per una universitat catalana, Barcelona, Institut d'Estudis Catalans, 20II, pp. 9-I2.

I9 Ídem, p. 7.

20 Jordi Monés Pujol-Busquets, El Congrés de 1903, Educació i Història. Revista d'Història de l'Educació, núm. 5, 200I-2002, p. I35. 
Universitari Català del dia 3I de gener al 2 de febrer de 1903 a Barcelona, on es va promoure la creació dels Estudis Universitaris Catalans, una universitat parallela i no oficial. ${ }^{21}$

En aquest context, una de les primeres accions que va fer Prat de la Riba l'any 1907 fou la creació de l'Institut d'Estudis Catalans, la tasca del qual era regularitzar i promoure els diferents aspectes de la cultura i de la llengua catalanes. El primer president de l'entitat fou Antoni Rubió i Lluch, el qual conservà el càrrec fins a l'any I9I5. Poc després, l'IEC es convertí en l'òrgan institucional per administrar el món de l'alta cultura catalana, convertint-se així en una de les organitzacions més destacades durant la Presidència de Prat de la Riba a la Diputació de Barcelona, entre els anys 1907 i 1917, i la Mancomunitat entre 1914 i $1923 .{ }^{22}$

L'any 1907, el Govern espanyol va crear la Junta de Ampliación de Estudios e Investigaciones Científicas, la qual depenia del ministeri d'Instrucció Pública. Basada en organitzacions similars creades per altres organitzacions estatals europees, aquesta institució promovia la connexió dels estudis universitaris del Regne d'Espanya en altres centres estrangers. A part de la influència fora de l'Estat, a la Junta admeteren, a les pàgines 50 i $5 \mathrm{I}$ de la memòria del primer any, que l'Institut d'Estudis Catalans era una referència pel que fa a la modernització dels coneixements en humanitats:

A más del ejemplo de otros países, hay ya una experiencia en España que justifica una cierta esperanza en que esa iniciativa ha de ser, más tarde ó más temprano, recogida.

Fundado mientras el proyecto análogo de la Junta se hallaba paralizado en el Ministerio, funciona ya en Barcelona un Institut d'Estudis Catalans, creado por la Diputación para la superior investigación cien-

2I Albert Balcells, Els Estudis Universitaris Catalans..., pp. I2-I6.

22 Ídem, pp. 45-52. 
tífica de todos los elementos de la cultura catalana; publicación de trabajos sobre Historia, Arqueología, Literatura y Derecho; formación de un Archivo y Biblioteca; apertura de concursos, conferencias, misiones de exploración, etc. ${ }^{23}$

Entre els anys I908 i I9II, es concediren les primeres beques de la Junta de Ampliación de Estudios. Els pressupostos del Govern espanyol destinaven més d'un milió de pessetes a sufragar més de 200 subvencions a fora de l'Estat. Com que la Junta disposava d'uns recursos econòmics molt superiors als que tenia la Diputació de Barcelona, l'administració Prat de la Riba aprofità la situació i va promoure que diversos estudiosos catalans obtinguessin les beques del Govern espanyol per anar estudiar a l'estranger. ${ }^{24}$ Fins i tot la Diputació de Barcelona, mitjançant l'IEC, va finançar algunes beques per a la realització d'estudis fora de l'Estat. ${ }^{25}$

La importància que la Diputació de Barcelona donà als becaris catalans a l'estranger es veié reflectida en un discurs titulat «En Prat de la Riba propulsor eminentíssim de la cultura catalana», llegit per l'escriptor i recent membre de la Lliga Regionalista Jaume Bofill i Mates el dia 23 de desembre de l'any $1910,{ }^{26}$ on destacà com era de primordial el fet que els estudiants anessin a altres indrets del món

23 Fèlix Villagrasa Hernández, Mancomunitat i ciència..., p. 23.

24 Jordi Casassas YMbert, La voluntat i la quimera: el noucentisme català entre la Renaixença i el marxisme, Barcelona, Pòrtic, 2017, pp. 166-167.

25 Joan Julià Muné, Pere Barnils..., p. 20.

26 Fou un discurs amb motiu de la publicació de la segona edició de «La Nacionalitat Catalana» d'Enric Prat de la Riba. Cal tenir en compte que aquest discurs formava part d'un homenatge organitzat per l'escriptor modernista Joan Maragall i Gorina per exaltar la figura del llavors president de la Diputació de Barcelona després dels convulsos esdeveniments de la Setmana Tràgica del juliol de l'any 1909, vegeu Albert Balcells, Els Estudis Universitaris Catalans..., pp. I2-I6. Sobre els anys de formació d'Enric Prat de la Riba, vegeu Giovanni C. Cattini, Prat de la Riba i la historiografia catalana: intellectuals i la crisi política a la fi del segle XIX, València, Afers, 2008. 
per absorbir la informació necessària amb l'objectiu de crear una Catalunya potent:

L'enviu (sic) de pensionats a estudiar o, més ben dit, a aprendre d'estudiar, d'investigar i d'organitzar, a l'estranger, ens és absolutament urgent indispensable. És l'única manera de provocar, com ha fet el Japó, una ràpida assimilació de cultura. És l'única manera d'improvisar el primer grau d'una civilització. ${ }^{27}$

Els destins més destacats dels pensionats foren la República Francesa, el Regne d'Itàlia, el Regne Unit, Bèlgica i els Estats Units d'Amèrica. Però hi hagueren molts becaris que també estudiaren a l'Imperi alemany. $^{28}$

\section{L'enviament de filòlegs al Deutsches Kaiserreich}

El Segon Reich alemany era un dels països amb un dels sistemes universitari més avançats del món a finals del segle xix i principis del xx. El sistema universitari havia gaudit en els territoris germànics d'un gran prestigi durant segles. Per exemple, el model creat pel baró Wilhem von Humboldt l'any I80s havia arribat a ser un dels més destacats a Europa. La fundació de l'Imperi alemany va accelerar el prestigi del sistema universitari germànic. A més, durant les més de quatre dècades que existí l'Alemanya guillermina, també augmentà la qualitat de les escoles tècniques, les quals es convertiren en la institució formativa del creixent sector serveis germànic. Socialment, les universitats i les escoles tècniques eren vistes per la puixant clas-

27 Jaume Bofill Mates, Prat de la Riba i la cultura catalana, Barcelona, Edicions 62, I979, p. 96.

28 Jordi Casassas Ymbert, La voluntat i la quimera..., p. I69.

Cercles. Revista d'Història Cultural, 24 (2021), 79-122.

ISSN: 1139-0158. e-ISSN: 1699-7468. DOI: 10.1344/cercles2021.24.1003. 
se mitjana de l'Imperi alemany com una via d'ascensió social. Per aquests motius, els professors universitaris i de les escoles tècniques alemanys gaudien d'un gran prestigi i reconeixement. ${ }^{29}$ Durant els últims anys del segle XIX i primers anys del segle Xx, el sistema universitari del Kaiserreich augmentà el nombre d'estudiants: dels II.00o estudiants que hi havia matriculats a les universitats alemanyes l'any I860, es passà a 60.000 estudiants l'any I9I4, dels quals 4.000 eren dones. ${ }^{30}$ Moltes de les universitats doblaren el nombre d'estudiants en pocs anys; per exemple, l'any I885, a les facultats de Dret hi havia apuntats 4.682 alumnes, mentre que a l'any I906, la xifra de matriculats havia augmentat fins a II.678. ${ }^{31}$

Les principals universitats de l'Imperi alemany estaven situades a Berlín, Breslau, Hamburg, Halle and der Saale, Leipzig, Jena, Munic, Tübingen, Bonn, Friburg de Brisgòvia, Estrasburg, Göttingen, Erlange, Würzburg, Marburg, Greifswald, Rostock, Kiel, Münster, Königsberg i Heidelberg. ${ }^{32}$

L'any 1907, amb l'arribada de Prat de la Riba a la Presidència de la Diputació de Barcelona, la creació de l'IEC i la concessió de les primeres beques per anar estudiar a l'estranger foren una oportunitat per a Manuel de Montoliu d'augmentar el seu prestigi com a acadèmic. Va ser en aquest context quan obtingué una beca de la Diputació de Barcelona per anar a estudiar a l'Imperi alemany. ${ }^{33}$ Les figures clau per entendre l'estada de Montoliu al Kaiserreich foren els filòlegs Antoni Maria Alcover i Bernhard Schädel.

Alcover, escriptor, sacerdot, folklorista i lingüista mallorquí, era conegut des de finals del segle XIX com a folklorista, amb obres com

29 Michael Stürmer, El Imperio alemán (I870-1918), Madrid, Mondadori, 2003, p. IO5.

30 Hagen Schulze, Breve historia de Alemania, Madrid, Alianza, 2019, p. 178.

3I Alfred OpIsso, Los Tres Imperios: Alemania, Austria-Hungria, Rusia: historia, su geografia, su arte y sus costumbres, Barcelona, Bastinos, 1906, p. 70.

32 Ídem, p. 70.

33 Joan Julià Muné, Pere Barnils..., p. 23. 
Contarelles, publicada l'any I885, i Rondayes, publicada el I896. L'any I90I, fundà la primera publicació filològica catalana titulada Bolletí del Diccionari de la Llengua Catalana (sic). Gràcies al Bolletí, Alcover es convertí en una de les figures més importants de la filologia catalana de principis del segle Xx, fins al punt que quan es creà l'IEC el 1907, es convertí en un dels màxims dirigents de la secció filològica. L'any 1906, fou l'organitzador i president del Primer Congrés de la Llengua Catalana, celebrat entre el i3 i el i8 d'octubre d'aquell any, l'objectiu del qual era orientar els estudis sobre la llengua catalana i redactar una gramàtica comuna per a tots els territoris de parla catalana. ${ }^{34}$ En aquest congrés, hi colllaboraren cinc acadèmics provinents de diferents facultats de l'Imperi alemany: Eberhard Vogel Müller, catedràtic de l'Institut i l'Escola Politècnica d'Aachen; els Privatdozent $t^{5}$ Bernhard Schädel i Albert Couson, de la Universitat de Halle; Johannes Fastenrath, des de Colònia; i el Karl Vollmöller, des de Dresden. ${ }^{36}$ D'aquests cinc acadèmics, fou Schädel qui més contacte tingué amb Alcover.

Bernhard Schädel fou el filòleg fora del Regne d'Espanya que més influí en l'obra d'Alcover. Schädel es doctorà l'any igor a la Universitat de Halle and der Saale amb una tesi titulada «Untersuchungen zur katalanischen Lautentwicklung», ${ }^{37}$ dirigida pel filòleg romanista Hermann Suchier. Viatjà dues vegades a Mallorca, una el I90I, on tingué contacte per primer cop amb mossèn Alcover i el I904,

34 Ídem, pp. I8-19.

35 Títol que significa professor no numerari que prepara per accedir al grau de numerari, equivalent a l'actual professor agregat o titular. El càrrec era de vital importància en el sistema universitari alemany, però el sou d'aquests professors era molt baix, ja que només cobraven per les taxes de matrícula dels estudiants. Vegeu Joan Julià Muné, Pere Barnils..., p. I8.

36 Antoni Alcover (ed.), Primer Congrés Internacional de la Llengua Catalana. Octubre de 1906, Barcelona, Estampa d'en Joaquim Horta, I908.

37 La traducció en català seria "Estudis sobre el canvi fonètic del català».

Cercles. Revista d'Història Cultural, 24 (2021), 79-122.

ISSN: 1139-0158. e-ISSN: 1699-7468. DOI: 10.1344/cercles2021.24.1003. 
per enllestir un treball titulat "Mundartliches aus Mallorca», ${ }^{38}$ publicat el 1905. L'any 1906, Schädel assessorà Alcover en l'organització del Primer Congrés Internacional de la Llengua Catalana, tot i que no pogué viatjar a Barcelona a causa d'un problema familiar. ${ }^{39}$

En una carta datada del 22 de març de l'any 1905, Schädel va escriure un agraïment a mossèn Alcover per participar en el Congrés Internacional de la Llengua Catalana que s'havia de celebrar l'octubre del 1906. En aquesta carta, el filòleg alemany proposava, entre altres coses, la preparació d'un equip d'investigadors lingüistes, ja que creia que calia promoure un estudi científic abans de la celebració del Congrés. En una llarga carta (28 pàgines), datada el I4 de juny de l'any I905, Schädel exposà el seu pla definitiu per a l'estudi de la llengua catalana. ${ }^{40}$

L'estiu del 1907, poc després de la creació de l'Institut d'Estudis Catalans, Schädel, que era colllaborador de l'entitat, proposà a Alcover i a Prat de la Riba un projecte per enviar uns quants joves perquè estudiessin filologia romànica a l'Imperi alemany, específicament a la seva Universitat, a Halle, al Regne de Prússia. A més a més, Schädel proposava que es dotessin beques per finançar els estudis durant tres anys que corresponien als sis semestres de les universitats alemanyes. El 26 de novembre de l'any 1907 la Diputació de Barcelona acordà dur a terme la proposta de Schädel, i va decidir convocar tres places per anar a estudiar a la Universitat de Halle. ${ }^{4 \mathrm{I}}$ En el text on s'aprova l'enviament dels pensionats, es remarcava que a les universitats del Segon Reich hi havia els recursos possibles per tirar endavant un bon estudi científic de la llengua catalana:

38 La traducció en català seria «Dialectes de Mallorca».

39 Joan Julià Muné, Pere Barnils..., p. I8.

40 Ídem, p. I9.

4I Ídem, p. 20. 
Estos estudios no pueden hacerse en nuestro país, porque no existen en España los elementos científicos necesarios para ello; en cambio en Alemania, se estudia, con gran profundidad, la filología de las lenguas románicas y allí es donde cabe estudiarse la de la Catalana y de sus dialectos. ${ }^{42}$

El filòleg alemany envià una carta a mossèn Alcover el dia 20 de desembre de l'any 1907 on fou molt insistent en la necessitat que la Diputació de Barcelona pagués tant el seu sou durant el temps que els pensionats estiguessin a Halle (com a Privatdozent, no cobrava ni de la Universitat ni de les administracions) com una beca anticipada als pensionats per tal de poder sufragar les despeses del viatge:

M'agradaria afegir-hi encara una petita cosa, relacionada igualment amb això: que no tinc cabals, ni rebo cap sou de l'Estat de Prússia. Així, doncs, si tot es realitza d'aquesta manera, seria imprescindible per a mi que aquesta quantitat fixada per al desenvolupament de la instrucció em fos pagada per avançat per la Diputació en un període determinat de temps, per exemple cada mig any o per trimestres, ja que pel que fa a mi es tracta dels cèntims que necessito per viure i que fins ara, com he dit, guanyava d'una altra manera. Si aquesta forma de pagament és possible, us prego que sigueu tan amable de comunicar-ho per escrit a Barcelona. També s'hauria de pagar anticipadament als 3 estipendiats les 3.000 ptes. anuals per a cadascun en sumes parcials durant diverses vegades a l'any, car altrament no podrien pagar-se a temps la subsistència ací. ${ }^{43}$

El dia 27 d'octubre de l'any 1907 es publicà a La Veu de Catalunya un anunci que deia el següent:

42 Fèlix Villagrasa Hernández, Mancomunitat $i$ ciència..., p. 24.

43 Joan Julià Muné, Pere Barnils..., p. 30. 
a) La creació de tres places per estudiar a Alemanya:

- Filologia de les llengües romàniques, especialment la catalana.

- Fonètica teòrica amb referències a la fonètica catalana.

- Lingüística catalana.

- Gramàtica històrica del francès i el provençal.

b) Una pensió d'una durada de tres anys per a cadascun, amb un pagament anual de 3.000 pessetes.

c) Els aspirants havien de realitzar les següents proves d'accés:

- Traducció i conversació del francès.

- Traducció del llatí i gramàtica llatina.

- Traducció de l'alemany.

- Exercicis per determinar l'aptitud auditiva per als estudis de fonètica.

d) El jurat qualificador estaria format per tres membres de l'IEC, un filòleg i un especialista en llengua alemanya.

e) L'assignació d'un pressupost extraordinari de 15.000 pessetes. $^{44,45}$

El dia Is de desembre de l'any 1907 aparegué el mateix anunci en El Poble Català. Teòricament les proves s'havien de realitzar durant la segona quinzena de setembre de l'any 1908. Finalment se celebraren el dia 2 d'octubre de l'any 1908 a les io del matí al Palau de la Diputació de Barcelona, situat en aquell moment a la plaça de Sant Jaume de Barcelona. El tribunal estava compost per:

- Antoni Rubió i Lluch, historiador, membre de l'IEC i president del Jurat.

44 Aquest pressupost no apareix a l'Arxiu de la Diputació de Barcelona, cfr. Joan Julià Muné, Pere Barnils..., p. 20.

45 Ídem, p. 24. 
- Guillem Maria de Brocà i de Montagut, jurista, historiador i membre de l'IEC.

- Jaume Massó i Torrents, director i fundador de la revista catalanista L'Avenç i membre del IEC.

- Mossèn Antoni Maria Alcover, el qual actuà com a filòleg i coneixedor de la llengua alemanya.

- Pompeu Fabra i Poch, filòleg i membre del IEC. ${ }^{46}$ En aquell moment Fabra estava a Bilbao per obligacions acadèmiques i per aquest motiu va delegar el seu vot a mossèn Alcover. ${ }^{47}$

Manuel de Montoliu coneixia a Mossèn Alcover des de principis de segle xx, fins i tot, havia participat en una comunicació en el Primer Congrés Internacional de Llengua Catalana amb el títol «Moviment assimilista de la literatura catalana en els temps moderns. Conveniencia de que es facin moltes traduccions i esments (sic) amb què cal fer-les». L'endemà d'aparèixer l'anunci de les tres beques en El Poble Català, Manuel de Montoliu publicà un llarg article titulat «La passió filològica», en el qual defensava la necessitat de fer estudis seriosos de filologia per elevar el nivell de competència dels intellectuals catalans i millorar acadèmicament aquest tipus d'estudis. Poc després, amb el vistiplau d'Alcover, Montoliu decidí presentar-se a les proves i envià una carta a Prat de la Riba el dia 26 d'agost de l'any I908 en què expressava la necessitat de desenvolupar les seves habilitats acadèmiques i no estancar-se professionalment:

Tinc una gran passió per l'estudi i no més desitjo trovar una ocasió per a satisfer els meus anhels i demostrar que esser útil en l'esfera de mes aficions literaries. Pero els anys passen i un es fa vell sense adonar-se'n, i espanta de que ha passat mitja vida sense haver pogut passar de la

46 Ídem, p. 2 I.

47 Ídem, p. 22-23.

Cercles. Revista d'Història Cultural, 24 (2021), 79-122.

ISSN: 1139-0158. e-ISSN: 1699-7468. DOI: 10.1344/cercles2021.24.1003. 
categoria d'aficionat per manca d'una situació apropiada al nostra ideal $[\ldots] .^{48}$

El filòleg tarragoní no fou el primer membre de la família Montoliu que viatjà a terres germàniques pensionat per les administracions. El seu germà gran, l'arquitecte Cebrià de Montoliu i de Togodes, que escrivia articles sobre problemàtica social per a El Poble Català, viatjà becat per la Junta de Ampliación de Estudios a l'Imperi alemany amb l'objectiu d'estudiar les societats cooperatives de crèdit, per tal d'impulsar l'edificació de barris obrers i facilitar-ne el finançament a partir de l'estalvi dels treballadors. ${ }^{49}$

Les proves a què foren sotmesos els examinats van ser les següents:

- Traducció d'un text llatí difícil al català: cap. III, Ad Demetrianum, de Sant Cebrià.

- Examen oral de gramàtica llatina: anàlisi de fragments del Llibre I de l'Eneida de Virgili.

- Conversa en francès: sobre literatura catalana de diverses èpoques.

- Traducció del català al francès: un fragment del Felix o Llibre de les Meravelles de Ramon Llull.

- Exercici d'aptitud per a la percepció fonètica: Destriar i qualificar els sons de diverses paraules franceses.

- Traducció al català d'un text facil en alemany: la segona rondalla de follets dels germans Grimm «Es war einmal ein armes Dienstmädchen... ${ }^{\text {s, } 51}$

48 Arxiu Nacional de Catalunya. Llegat de la família Prat de la Riba Dachs: ANCII37-T-IO46.

49 Jordi Castellanos, Intel.lectuals, cultura i poder, Barcelona, Edicions La Magrana, I998; pp. IO2-I5O.

50 La traducció en català seria "Hi havia una vegada una pobra minyona...».

5I Joan Julià Muné, Pere Barnils..., p. 23. 
El 4 d'octubre es van publicar els resultats en El Poble Català i els guanyadors foren Manuel de Montoliu, Antoni Griera i Gaja i Pere Barnils i Giol, els dos últims provinents de la comarca d'Osona.

Montoliu publicà el seu últim article de la secció literària d' $E l$ Poble Català el dia 2 de novembre de l'any 1908 , sota el títol «Lletres catalanes. Comiat». En el començament d'aquest article, Montoliu explicava als lectors d'El Poble Català que el dia 6 de novembre arribaria a la Universitat de Halle becat per la Diputació de Barcelona:

El dilluns que vé, si Déu vol, amics llegidors meus, us escriuré la meva acostumada crònica desde terra extrangera, desde Alemanya, on tinc d'estar absent de la meva volguda terra durant tres anys pera dedicarme a l'estudi de la Filosofia. Permeteume, doncs, que sortintme avui de la rigidesa del tema literari que m'imposa la meva obligació setmanal, m'entregui ab vosaltres comentant la significació del meu viatge y del dels meus companys que ab envia la nostra Diputació a estudiar en terra extrangera. ${ }^{52}$

En el mateix article, Montoliu remarcà que el fet d'anar a estudiar a l'estranger ajudaria a modernitzar el camp acadèmic català, el qual considerava que estava antiquat:

Catalunya [...] està cercant el seu destí y no'l troba. Y no'l trobarà fins que estrant resoltament en aquesta segona etapa acabi d'aclari y d'illuminar les seves orientacions del seu instint, les impulsions innates de la seva intuïció, que han produït l'originalitat exontania del seu art y la seva literatura, ab la llum de la coneixensa plenament disciplinada, ab l'acceptació y l'assimilació del regim de ciencia implantat en totes les manifestacions de la seva vida, que'ns dotarà del sentit orgànic que tant ens manca pera arribar a constituir un poble verament modern. ${ }^{33}$

52 Manuel de Montolıu, «Lletres catalanes. Comiat», El Poble Català, any V, núm. $992(2 / \mathrm{II} / \mathrm{I} 908)$, p. 3.

53 Ídem, p. 3.

Cercles. Revista d'Història Cultural, 24 (2021), 79-122.

ISSN: 1139-0158. e-ISSN: 1699-7468. DOI: 10.1344/cercles2021.24.1003. 


\section{Estada a l'Imperi alemany (1908-1911)}

\section{Els primers anys a Halle (1908-1910)}

El dia 6 de novembre de 1908, Manuel de Montoliu arribà a la ciutat de Halle acompanyat de la seva dona i el seu fill. Barnils i Griera havien arribat a la ciutat alemanya a mitjans d'octubre. Els becats foren rebuts pel Dr. Schädel, el qual preparà l'allotjament i la matrícula a la Facultat de Filosofia de la Universitat de Halle per començar de seguida que fos possible el curs semestral d'hivern. ${ }^{54}$ Durant el temps que va ser a l'Imperi alemany, Montoliu no només es dedicà a estudiar les matèries per a les quals havia sigut becat sinó també per analitzar documentació catalana, especialment medieval, que estava situada a diferents arxius i biblioteques repartits pel Segon Reich, feina de la qual Prat de la Riba també n'estava al càrrec."5

Halle and er Saale era capital de la província prussiana de Saxònia, ${ }^{56}$ actualment el land de Saxònia-Anhalt, situada a la ribera del riu Saale, afluent del riu Elba. En aquella època tenia al voltant de I60.000 habitants, i constituïa un centre miner, industrial, comercial i universitari important. La seva Universitat, seu de la FriedrichsUniversität Halle-Wittenberg, era coneguda per les seves classes de teologia i filosofia, que incloïa la filologia romànica. La Universitat de Halle havia estat fundada el I2 de juliol de I694 pel príncep Friedrich III von Hohenzollern, elector de Brandenburg, que a partir del I9or fou el primer rei de Prússia amb el nom de Frederic I. Fou considerada la primera universitat moderna de terres germàniques. A partir de l'any I817, la Universitat de Halle es fusionà amb la de

54 Joan Julì̀ Muné, Pere Barnils..., p. 25.

55 Arxiu Nacional de Catalunya. Llegat Puig i Cadafalch: ANCI-I37-T-2797.

56 No s'ha de confondre la província de Saxònia que estava dintre del Regne de Prússia amb el Regne de Saxònia, la capital del qual era Dresde. 
Wittenberg, i així es creà la Friedrichs Universität Halle-Wittenberg. La seu que tenia l'any 1909 era la mateixa des de $1834 .{ }^{57}$

Un dels primers articles que Montoliu escrigué per a El Poble Català es titulava "L'Universitat de Halle», i fou publicat el dia I4 de desembre de l'any 1908. En aquest article, Montoliu admirava l'eficiència del sistema universitari alemany i com l'especialització del professorat feia, paradoxalment, que hi haguessin catalans que anessin al Kaiserreich per estudiar la seva pròpia llengua:

D'aquí resultà també una indefinida especialització de les coneixenses, ja que per preocuparse deixebles tant els "privatdozents», com els "professors» fujen de les materies generals que, té per má la majoria, y agafan una branca desconeguda o poc estudiada de la seva materia pera ferse valer y fer, tant com sía possible, indispensables llurs estudis y ensenyanses. Aquesta tendencia moderna vers una progressiva especialisació de la ciencia que infaliblement resulta d'aquesta organisació, esplica el fet, que potser a molts els deu semblar inexplicable, de que tres catalans hagin de sortir de Catalunya y anar al estranger pera estudiar al catalá. No el catalá, sino el dialecte o varietat dialectal que's parla en el més ignorat recó de Catalunya, tindrem d'anar a estudiar a Alemanya o a un altre pais estranger $[\ldots] .^{58}$

Una de les coses que cridaren més l'atenció a Montoliu fou la figura del Privatdozent, perquè considerava que, a diferència dels professors auxiliars de les universitats del Regne d'Espanya, no estava supeditada completament als designis dels catedràtics:

[...] que no és, com sembla, a primer cop de vista, lo que aqui en diem un «auxiliar», sinó un contricant, un rival del professor oficial, que ai-

57 Joan Julià Muné, Pere Barnils..., p. 25.

58 Manuel de Montoliu, "L'Universitat de Halle», El Poble Català, any V, núm. IO34 (I4/I2/I9O8), p. 2. 
xeca càtedra davant de ell pera ensenyar les mateixes matèries y no estudia, ab emportàrseli els estudiants i deixarlo sense alumnes, perquèls estudiants tenen aquí plena facultat d'elegir el professor que vulguin, cosa que poden fer sempre, car se troben al menys ab dos catedràtics que'ls poden ensenyar la mateixa materia, sense comptar ab la llibertat absoluta de traslladarse d'una universitat a qualsevulga altra. ${ }^{59}$

Montoliu i la seva família s'instal.laren juntament amb Griera i Barnils en una casa situada a la mateixa escala que viva Bernhard Schädel, a la Richard-Wagner-Strasse, 43. El dia 22 de novembre de I908, poc després d'arribar a Halle, Montoliu escrigué una carta a Prat de la Riba on explicava la situació en què es trobaven els catalans que havien viatjat a l'Imperi alemany. Primer de tot, Montoliu detallava com Schädel havia adoptat un pla d'estudis per aconseguir la ràpida adaptació dels becats, ja que entre altres coses, no dominaven la llengua alemanya:

El Dr. Schädel ens ha fet variar el plà d'estudis senyalat en el projecte y crec que ha estat encertat. Segons el plà esmentat, durant el rer semestre, no més teniem de dedicarnos al alemany y el Dr. Schädel ha cregut que fora convenient que comencessim ab ell un curs de nocions de fonètica y filologia catalanes que per ara ens explica en francès, $\mathrm{y}$ al mateix temps ens ha fet matricular à l'Universitat ont anem a escoltar alguns cursos de caracter general per a que'm acustumem à sentir y ens esforcem en compendre l'alemany. Aquesta llengua, es realment terrible; la dificultat no vé precisament de la materialitat de la llengua, del vocabulari, sinó de la peculiar constitució cerebral que tenen aquesta gent, que per força ha d'esser difenta de la nostra, puix construeixen ab una llogica diametralment distinta de la nostra, y fins que un no les arrivat à assimilarse aquesta llògica especial de la llengua alemanya, es inutil que intenti parlarla y compéndrela del tot. Mes en fi, jo hi poso els meus cinc

59 Ídem, p. 2.

Cercles. Revista d'Història Cultural, 24 (2021), 79-122. ISSN: 1139-0158. e-ISSN: 1699-7468. DOI: 10.1344/cercles2021.24.1003. 
sentits y totes les meves forces pera posseir aviat la llengua d'aquest pais, y crec que en el segon semestre, lo mateix per'ls meus companys, ja estaré en disposició de treure profit dels cursos de l'Universitat. ${ }^{60}$

Posteriorment, Montoliu exposà en la seva carta l'admiració que sentia per la riquesa cultural de la ciutat de Halle, i especialment quedà meravellat del funcionament de la Universitat:

En quant à la vida, aquí es molt agradable, en primer lloc per la gent que es sumament civilisada y tambe per la ciutat mateixa que es tota bonica y riallera. Se veu que la seva importansia es de poc temps perque quasi tota l'estensió de la ciutat actual està cupada per edificis moderns y la part històrica, per cert, molt interessant, està reduida à un perimetre molt petit. A Alemanya diuen de Halle que es una ciutat de savis; y realment es la vida estudantil y universitaria que li posa el seu cachet. De l'Universitat mo'n sabria pas descriure l'impressió que n'he rebut: pera mi, es la descoberta d'un nou mon. Quina serietat, quina inmensitat de coneixaments y especialitats, quina intensitat de treball intelectual! Qui pogués passarhi 6 anys o 7 en una Universitat aixi! ${ }^{61}$

Finalment, Montoliu sol.licità a Prat de la Riba un augment econòmic per poder subsistir la seva família i continuar els seus estudis de documents catalans situats en diferents biblioteques i arxius del Segon Reich:

I ara perdoni si li torno a recordar aquell assumpto de que li vaig parlar avans de partir. A la Companyia de Filipines ont estava empleat m'han concedit uns pocs mesos de sou que'm permeten aguantar la situació per ara. Pero a principis d'any necessitaré ab tota precisiò un aument

60 Arxiu Nacional de Catalunya. Llegat Puig i Cadafalch: ANCI-I37-T-2797.

6I Ídem. 
en la meva assignació si vull continuar els meus estudis. Aixi, doncs, li agrairia $a b$ tota l'ànima que a primers de Janer jałm pogués dir alguna cosa del cert. A Alemanya per lo que he sentit à dir aquestes dies hi ha gran riquesa de manuscrits y falta molt encare pera espigolar en aquest camp pera trovar documents catalans. Es una feina que la podré fer comodament perque puc aprofitar les festes y sobre tot als mesos de vacacions que son uns quatre al any. Donat lo que costa aqui la vida y lo precis que necessito pera la sustentació de la meva familia, aquesta nova consignació m'hauria de suposar un mínimum de 125 ptas al mes (I.500 ptas anuals). He volgut precisarli aquests detalls perque aixi V.[ostè] se pugui formar carrec complet de la meva situació y pugui obrar en conseqüència. Ja sap V.[ostè] y no cal repetirli l'agraiment que tota la ida li sere ací per haverme ajudat y costingut ab son bons oficis en aquesta fase trascendental de la meva vida. ${ }^{62}$

Les dificultats econòmiques foren un dels maldecaps més importants que van haver de patir el grup de catalans que va anar a Halle. La situació econòmica era tan complicada que els tres pensionats, juntament amb Júlia Vidal, muller de Montoliu, la qual era violinista professional, crearen un grup musical amateur per tal d'augmentar els seus escassos recursos. ${ }^{63}$

Fins i tot, des d'abans de l'arribada dels pensionats, Schädel sollicitava constantment un augment d'ingressos a la Diputació de Barcelona per tal de sufragar les despeses de la tutoria dels estudiants catalans. Dies abans de l'arribada de la família Montoliu i Vidal a Halle, Schädel envià una carta el dia 27 d'octubre de 1908 a mossèn Alcover, on demanava un augment del sou per les despeses dels becats i també per al seu propi manteniment econòmic:

62 Ídem.

63 Joan Julià Muné, Pere Barnils..., p. 25. 
Naturalment estic ben disposat cada 3 mesos a enviar un rebut a Prat de la Riba, que, com deia, importi cada cop I075 marcs; només que m'és impossible de viure si cobro a la fi de cada trimestres (3 mesos). Jo he de fer tots els pagaments per la seva subsistència per avançat; els grans, com el lloguer, cada 3 mesos; els petits, cada mes. Aquesta és la nostra llei i el nostre costum. Si ara no rebia la remuneració dels tres primers mesos fins a la fi d'aquest període, no tindré cap més remei que patir gana, si no trobo mitjans pecuniaris, des del is d'octubre de I908 fins el is de gener de I909; en altres mots, des de l'inici de la meva tasca amb els estipendiats i d'ençà que vaig deixar de percebre els meus anteriors ingressos. No em resta altra cosa que fer-vos amablament el prec que us adreceu a Prat de la Riba per explicar-li aquesta qüestió i demanar-li que, tal com jo desitjaria, em facin efectiva la compensació no a la fi sinó al començament de cada trimestre, i, conseqüentment, pel que fa al present trimestre no dintre de 3 mesos sinó inmediatament. Si calia, d'altra banda, enviar-li un rebut, us demano, si teniu l'amabilitat, una resposta immediata i la indicació de la forma en què se solen fer, segons el costum espanyol, tals rebuts [...].

La Diputació va lliurar als estipendiats poc abans de la seva partenença la quantitat per a 3 mesos: 750 ptes. Els estipendiats, però, a l'inici dels seus estudis no han de pagar solament el viatge a Halle, sinó també els drets de matrícula per al primer semestre (2 trimestres), els llibres imprescindibles, i finalment, ja que han vingut gairebé sense roba d'hivern ni roba interior, han de comprar articles d'ús imprescindible. Aquestes són coses el cost de les quals es distribueix en un període més llarg que el del primer trimestre. Si els estipendiats han de pagar puntualment les seves compres, és necessari que cobrin a la bestreta no 3 mesos, sinó, almenys al començament, 6 mesos. Al capdavall, us he de participar amb satisfacció que els estipendiats han trobat tot el que necessiten encara més barat, en comparació amb el pressupost que havia fet abans i que sortia per un càlcul de 3.000 ptes. $^{64}$

64 Ídem, pp. 3I-32.

Cercles. Revista d'Història Cultural, 24 (2021), 79-122.

ISSN: 1139-0158. e-ISSN: 1699-7468. DOI: 10.1344/cercles2021.24.1003. 
Quan Alcover rebé la carta de Schädel, escrigué un seguit de cartes a Prat de la Riba exposant les demandes que l'home plantejava per al bon funcionament dels estudis fets a Halle. El dia io de desembre de l'any 1908, Prat de la Riba contestà el següent:

En quant a lo passat son coses inevitables en corporacions formades per molta mena de gent y en que's resolen a cada reunió moltitut d'assumptos. La Comissió va acordar pensionar tres joves a Alemanya de conformitat ab les bases que V. [ostè] va enviarme y que varen ser integrament llegides pel Secretari en la reunió. En aquestes bases s'hi comprenien dugues parts: pensió a tres estudiants y organisació d'unes ensenyances especials complementaries de les que's donen a la Universitat de Halle. Per lo primer volien 9.00o pts; per lo segon 6.000; total, I5.000. Pero el Secretari al formular el dictamen per la sessió de la Diputació, si be en els considerandos va consignar totes dugues coses mes o menys precisament, va descuidarse de posar en la part dispositiva que a la organisació de les ensenyances especials s'hi destinaria 6.000 pts., $\mathrm{ab}$ tot y que en el mateix dictamen se diu que per aquestes pensions se senyala un credit de 15.000 pts., y que no mes s'en fixa 3.000 a cada un dels tres pensionats. -Per lo mateix, jo vaig creure que l'acort era tal com voliem que fos, $\mathrm{V}$.[ostè] sap prou que se llegeixen els dictamens en les corporacions publiques. Y no vaig enterarme de que hi hagues dificultat, fins aquest istiu quan al parlarne al Secretari, sempre m'hi trobava inconvenients y dilacions, presentant objeccions sense gaire valor. El veritable motiu el vaig descubrir al ferme dur l'expedient: allavors vaig veure l'omissió que hi havia en el dictámen, omissió que exigeix un nou acort de Diputació. ${ }^{65}$

Tot i la voluntat de Prat de la Riba per solucionar aquesta situació, la partida pressupostària que oficialment donà la Diputació de Barcelona als tres pensionats a Halle foren un total de 6.750 pessetes

65 Ídem, pp. 3I-33. 
entre l'octubre del 1908 al setembre del I9II, és a dir, 2.250 pessetes per cada becat. ${ }^{66}$

Durant els primers mesos de la seva estada a la ciutat, els tres becaris combinaren la Universitat amb les classes particulars que Schädel impartia en un local que havia llogat en el mateix edifici que vivien i que havia dotat d'una biblioteca especialitzada, amb llibres de català i romanística per als tres pensionats catalans, per facilitar-los els exercicis i el treball en comú. A més a més, passaren el primer semestre estudiant alemany i fent intercanvi lingüístic català-alemany i castellà-alemany amb estudiants alemanys que preparaven tesis de doctorat sobre el català o el castellà. A banda, Montoliu, Barnils i Griera assistiren a nombroses classes d'art, història i geografia per acostumar-se a la llengua alemanya. Pel que fa els estudis de filologia, els tres pensionats reberen classes de Schädel principalment de gramàtica històrica, i de fonètica general i catalana. ${ }^{67}$

El dia I4 de gener de I909, Manuel de Montoliu envià una carta a Prat de la Riba per posar-lo al dia de la seva situació. El primer que s'observa és que a principis de l'any 1909, el filòleg tarragoní ja no estava allotjat a l'edifici on residien els altres pensionats catalans. Després, s'hi veu que estava satisfet per l'evolució de les seves investigacions, per la bona relació que tenien els pensionats catalans amb Schädel i perquè els diners assignats per la Diputació de Barcelona el I908 havien arribat. Fins i tot, Montoliu explicava en aquesta carta que havien assistit a classes del professor Hermann Suchier, el qual havia sigut director de tesi de Bernhard Schädel:

No puc negar que havia vingut aqui ab un cert recel, ab cert escepticisme sobre el profit que podria treure d'uns estudis empresos ab una llengua desconeguda y dificilíssima, Pero avui, al cap de mesos d'estada

66 Ídem, p. 33.

67 Ídem, p. 27.

Cercles. Revista d'Història Cultural, 24 (2021), 79-122.

ISSN: 1139-0158. e-ISSN: 1699-7468. DOI: 10.1344/cercles2021.24.1003. 
en aquest pais, havent vist els grans progressos que ja he fet en entendre y parlar l'alemany, me trovo plé de coratge y d'ilusió, sobre tot considerant que tinc al meu costat aquest savi y simpàtic Sr. Schädel que's desviu materialment per nosaltres, y ens inicia d'una manera admirable y ab una metòdica graduació en aquest intrincat laberint de Filologia moderna. Confiem molt fundadament tots tres pensionistes que durant el semestre següent estarem ja suficient ensinestrats en l'alemany pera pendre part activa en les classes de l'Universitat ont anirem al curs de Filologia romanica den Suchier. Per ara son nocions y elemenys lo que'ns ensenya el Dr. Schädel; ens ha ensenyat detalladament el seu sistema de transcripció fonètica que ja comencem à dominar, y analisem filologicament, en especial en la part etimològica, el texte del Llibre d'Amic y Amat den Llull. El Dr. Schädel ens parla també molt sovint de tot lo que manca à fer per l'estudi cientific de la nostra llengua; y tots els seus projectes sobre'ls nostres treballs futurs y la prespectiva de dotar à la nostra terra d'una cultura filològica digna dels temps moderns, ens donen el coratje y el entussiasme necessaris pera sortir airosos de la dificil tasca que en el curt espai de tres anys em toca realisar $\left[\ldots . .{ }^{68}\right.$

Però, en la mateixa carta, Montoliu, com els altres pensionats, demanava a Prat de la Riba si la Diputació de Barcelona podia enviar més diners, ja que considerava que estaven econòmicament al límit. Fins i tot, el filòleg tarragoní afirmà que tornaria a la seva antiga feina a Barcelona, a la Compañía de Filipinas, si no hi havia més compensació financera:

Solament, amic Prat, hi ha, per lo que à mi toca, un punt negre, que m'ompla d'inquietut. Mentres no estigui resolt l'assumpte del qual li vaig parlar sobre l'aument de la meva pensió, no puc estar tranquil i no puc tenir la seguretat de poder continuar sostenintnse en l'estranger

68 Arxiu Nacional de Catalunya. Llegat Puig i Cadafalch: ANCI-I37-T-2797. 
durant els tres anys. Ara tinc aquí la meva dona y el meu nen; y si podem aguantar es gracies à unes poques mensualitats que, com una mercè especial, me va concedir la "Compa[ñia] de Filipinas" ont, com sap V. [ostè], estava empleat. Un cop acabats aquests fondos, si no'ns vé un reforç per part de la Diputació, la meva situació es inssostenible, Encare que aqui la vida no resulti cara, $V$. [ostè] compendrà que ab els 50 ptes. mensuals de la Diputació no'ns basta per viure als tres que som de familia. Ha de considerar també que cada semestre me toca gastar al menys Ioo M[arc]s, de matrícules y que tinc d'estaliar després del $4 \mathrm{t}$ semestre el viatge d'investigació filològica per Catalunya que'l Dr. Schädel te en projecte. Tot aixo'm posa sumament angustiós; y si no's resol aviat l'aument que V. [ostè] em va prometre per medi de l'encàrrec de la copia de manuscrits, à primers de Març me veuré obligat à tornar à Barcelona pera encamarme de nou en la meva oficina. ${ }^{69}$

Des de la Diputació de Barcelona i l'Institut d'Estudis Catalans es veié amb preocupació el fet que Montoliu volgués tornar a Barcelona. Josep Pijoan, secretari de l'IEC, que havia fet estudis d'art al Regne d'Itàlia entre els anys 1903 i I904, escrigué una carta a Manuel de Montoliu el dia 20 de març de l'any 1909 en la qual animava a continuar els seus estudis a Halle malgrat els problemes de pressupost, ja que la seva tasca estava ajudant al prestigi de l'IEC:

Hem de fer tots els possibles perque tu t'aguantis aquí els tres anys, ho necessitem molt tots. Tu necessites per això un suplement de ingresos que t'ajudi en lo que no arriba la Diputació. Jo se per experiencia lo que es aixo de trobarme sol en pais foraster a careixer de lo necessari y de l'espant que dona aquesta soledat $[\ldots]$.

Pro t'has de convencer [...] que'l teu treball sigui eficas y util, perque tingui que durar tots tres anys. Si lo que fessis, fos una cosa poch important o discutible, ab el pressupost de l'Institut, que no es gran y

69 Ídem. 
que serà magre ab el temps, s'et discutirà y s'et suspendría aquesta ajuda. ${ }^{70}$

Durant els semestres següents es continuà el programa d'estudis aprovat per la Diputació de Barcelona, tot i que no sempre es va seguir al peu de la lletra. ${ }^{71}$

\section{El trencament amb Schädel (1910-1911)}

L'any i9ıo la relació entre els pensionats i Schädel es truncà. Mesos abans, un cop acabades les classes de fonètica general, els becaris catalans havien fet un treball sobre la transcripció fonètica catalana. Schädel havia comprovat els resultats i els havia publicat al Bulletin de Dialectologie Romane de Brussel.les a principis d'aquell any amb el títol «Über Schwankungen und Fehlergrenzen beim phonetischen Notieren $»^{72}$. Montoliu, Barnils i Griera s'enfadaren perquè el filòleg alemany s'havia apropiat de les investigacions i havia relegat els becats catalans a informants en algunes referències de l'article. Schädel al.legava que estava en el seu dret de triar, citar o no els seus informants i que podia fer les seves investigacions segons el seu parer. Aquest fet, més el control continu que exercia sobre els seus estudiants i la poca acceptació de les crítiques que es feien als seus estudis acadèmics i dels pensionats catalans, va provocar un seguit de cartes enviades a Alcover i a Prat de la Riba per part dels pensionats i de Schädel mateix, en què s'acusaven mútuament de no haver complert els reglaments establerts pel pla d'estudis. ${ }^{73}$

70 Biblioteca de Catalunya. Fons Montoliu: MS.3II4.

7I Joan Julià Muné, Pere Barnils..., p. 28.

72 La traducció en català seria «Fluctuacions i aproximacions en les anotacions fonètiques».

73 Joan Julià Muné, Pere Barnils..., pp. 29-30. 
D’una banda, Bernhard Schädel deia que els estudiants catalans no treballaven prou ni de la manera adequada. A més, argumentava que Montoliu, Barnils i Griera eren poc disciplinats en el compliment dels seus deures respecte al pla de treball en general i al treball de camp en particular, el qual els becaris es negaven a realitzar, fet que Schädel considerava inadmissible. Per aquest motiu, el filòleg alemany considerava que els becats no podien assolir de cap manera el nivell de coneixements ni de formació que s'havien marcat. Per tant, Schädel creia que els pensionats no tenien cap dret a desautoritzar-lo, ja que no s'esforçaven com requeria el nivell d'estudis ni li tenien prou respecte.

D'altra banda, els pensionats catalans creien que Schädel no tenia dret a cobrar de la Diputació de Barcelona perquè el nivell de les classes que impartia no era el promès. A més, es queixaven que Schädel els volia monopolitzar i controlar amb excés, sobretot a partir del tercer semestre. Finalment, consideraven que el filòleg alemany els hauria d'haver fet més cas i orientat cap a noves assignatures i nous coneixements. Un exemple de les crítiques contra Schädel fou una carta de Manuel de Montoliu enviada a Prat de la Riba el I7 de febrer de I9IO on atacà durament el filòleg alemany i li demanà que ell i mossèn Alcover es posicionen a favor dels pensionats:

Com vol V.[ostè] que callessim els pensionats y que no denunciessim la manca d'interès per nosaltres, les faltes de consideració personal, la negligencia de les seves ensenyansa en aquest semestre, la falta de preparació en molts punts del nostre programa com son el provençal y la critica dels antics textos, l'abus intolerable que fet fentnos pagar en matricules d'Universitat lliçons que eren pagades especialment per la Diputació, els obstacles que ha oposat als nostres treballs particulars tot perque no anessim massa despressa y podernos entretenir durant els tres anys etc. etc.? No; no ha sigut sol el revolucionari [...] Montoliu el que s'ha exaltat davant de tant abús y de tanta frescura (no trovo 
altra paraula) sino adhuc el timit company Sr. Griera ens prenem massa en serio els nostres estudis per tolerar que's jugui ab nosaltres y ab la nostra formació científica. ${ }^{74}$

Després de rebre els arguments de les dues parts, Alcover i Prat de la Riba decideixen deslliurar-los dels seus compromisos. Schädel fou acomiadat de la tutoria dels pensionats catalans i del contracte amb la Diputació de Barcelona. D'altra banda, els becats foren alliberats de l'obligació de donar comptes a Schädel i, en conseqüència, disposaren de llibertat per escollir un programa d'estudis diferent, sempre que estigués dintre del pla d'estudis aprovat per la Diputació i amb l'acord d'un nou tutor. Durant els mesos següents, la Diputació de Barcelona continuà donant suport els becats a Halle, fins i tot ja se'ls estava preparant per treballar amb feines de filologia a l'Institut d'Estudis Catalans, tal com ho expressa el mateix Prat de la Riba en la memòria anual de la Diputació de Barcelona el dia 29 de novembre de l'any i9ıo:

[...] els pensionats de filologia no han tornat encara, però en acabar els seus estudis, podrien treballar profitosament en les Oficines del Diccionari de la Llengua Catalana a organitzar per l'Acadèmia corresponent del nostre Institut. ${ }^{75}$

A partir d'aquest episodi, els quatre filòlegs seguiren camins ben diferents. ${ }^{76}$

Bernhard Schädel deixà la Universitat de Halle l'any i9ıi per obtenir una plaça de Filologia Romànica en el Kolonialinstitut de Hamburg (el qual es convertí en universitat l'any 1919) i va fer-se

74 Arxiu Nacional de Catalunya. Llegat Puig i Cadafalch: ANCI-I37-T-2797.

75 Joan Julià Muné, Pere Barnils..., p. 37.

76 Ídem, pp. 29-30. 
càrrec del Seminar für romannische Sprachen und Kultur, un dels seminaris de filologia romànica més prestigiosos del Segon Reich Alemany, on creà posteriorment l'Ibero-Amerikanisches Institut. Fins a l'any I9I9 no es reconcilià amb els antics pensionats a Halle. ${ }^{77}$

Barnils fou l'únic dels tres pensionats que complí els sis semestres d'estada a la Universitat de Halle, amb Hermann Suchier com a nou tutor. Després que li concedissin una pròrroga econòmica per part de l'IEC per estudiar entre Alacant, París i Halle els anys I9II i I9I2, el I9I3 publicà la seva tesi doctoral amb el nom de «Die Mundart von Alacant. Beitrag zur Kenntnis des Valencianischen ${ }^{7^{8}}$. D'altra banda, Antoni Griera cursà els seus últims semestres a la Universitat de Zuric, on estudià amb el lingüista i romanista Louis Gauchat. L'octubre del I9II es doctorà amb una tesi titulada "La frontera catalano-aragonesa». ${ }^{79}$ Griera envià una postal des de Zuric a Manuel de Montoliu, el qual continuava a Halle, el dia I de novembre de I9Io, $\mathrm{i}$ hi explicava les dificultats econòmiques que patia a causa de com li resultava de cara la ciutat suïssa:

Estimat Manel; carregat de culpa i vergonya gayrabé no goso contestarte després de tants dies.[...] Ioo pts tenia del semestre d'istiu i encara no podré arrivar. Mira l'Universitat sola m'ha costat ${ }^{6} 63$ frcs. Rodons. el consolat 5, dos dies d'Hotel 20, viatge 72, llibres 60; figurat com puc estar aci solitari sense una persona coneguda no hi puc quedar sense un xavo figurat tinc uns 300 frcs fins qu'arrivi'l trimestre $\mathrm{i}$ noy me trovo espantat. [...] La vida ací es caríssima. [...] Ja ho veus Manel! Estem condemnats a la miseria. ${ }^{80}$

77 Ídem, p. 35.

78 La traducció en català seria «El dialecte d'Alacant. Contribució al coneixement del valencià».

79 Joan Julià Muné, Pere Barnils..., p. 38.

80 Biblioteca de Tarragona. Llegat Manuel de Montoliu.: ST oI7:027.I (467.I)LLE. 
A partir de la segona meitat de l'any I9ıo, la notícia del conflicte entre Schädel i els pensionats es va fer pública. Però hi hagueren mitjans de comunicació que en van informar erròniament, com fou el cas d'El Poble Català, explicant que foren els tres pensionats els que tornaren a Barcelona. En una carta al director d'El Poble Català, titulada «Rectificació», publicada el I4 d'agost de I9Io, Montoliu hagué d'aclarir que només Antoni Griera havia tornat a Barcelona (tot i que viatjà a Zuric poc després). També va comentar que ell $\mathrm{i}$ Pere Barnils es quedarien a l'Imperi alemany per tal de complir el pla que la beca concedida per la Diputació de Barcelona establia. ${ }^{81}$

Montoliu continuà pensionat a l'Imperi alemany durant els últims mesos de igro i els primers mesos de igir. Durant aquest període, el filòleg tarragoní, juntament amb Pere Barnils, rebé classes particulars de llengua provençal amb el professor Suchier. A més, com ja s'ha vist, Montoliu aprofità els dies festius per anar a diferents ciutats de la geografia alemanya a consultar documentació literària catalana que estava repartida en biblioteques i arxius del Kaiserreich. Per la documentació conservada, es pot intuir que tingué contacte amb diferents ciutats alemanyes: Dresden, Leipzig, Spremberg, Hamburg o Stuttgart. ${ }^{82}$

\section{Opinions sobre el sistema universitari alemany}

Durant el temps que estigué a Halle, Montoliu continuà escrivint articles per al diari El Poble Català. Els escrits publicats en el diari catalanista progressista a partir del gener de l'any 1909 portaven el títol de "Coses d'Alemanya». En aquests articles, Montoliu va escriu-

8I Manuel de Montoliu, «Rectificació», El Poble Català, any VII, núm. 1989 (I4/8/I9IO), p. 2.

82 Biblioteca de Catalunya. Fons Montoliu: MS.3II4. 
re sobre tota mena de temàtiques: política, societat, ideologia, etc. Durant els anys que va viure a Halle, els articles de Montoliu a El Poble Català foren considerats com una de les cròniques més destacades sobre l'Imperi Alemany que es rebien a Catalunya. ${ }^{83}$

Una de les temàtiques que Montoliu tractà en els articles "Coses d'Alemanya» fou també el sistema universitari del Segon Reich, del qual era un gran admirador. Un exemple d'aquesta simpatia pel món acadèmic de l'Imperi alemany fou un article titulat «Coses d'Alemanya. El centenari de La universitat de Berlín», publicat a El Poble Català el dia 22 d'octubre de I9Io. Montoliu es congratulava del centenari de la Universität zu Berlin, fundada pel lingüista Wilhelm von Humboldt l'any i809. Pel filòleg tarragoní, la creació de la Universitat de Berlín havia sigut el fonament d'un potent sistema universitari alemany, el qual no havia parat de créixer des de la creació de l'Imperi l'any i87I:

Recordem, recordem amics meus, perquè aquests records [del centenari] són un poderós estímul pera tots nosaltres, recordem que la Universitat de Berlín, ont cremà la primera flama impulsora de tot aquest gegant mecanisme de l'Imperi alemany, fou fundada en un temps en el qual Alemanya, estava políticament per terra. Aquesta fundació fou una empresa heroica que portaren a cap uns quants esperits vidents decidits a reemplassar per medi de la activitat intelectual lo que mancava a la nació d'importancia política. Desde l'any 70, Alemanya ocupa un lloc preeminent entre les primeres potencies; y mal que durant molt temps s'hagués cregut que tota la grandesa d'Alemanya no passaria de la grandesa de la seva ciencia y que el poble alemany era un poble de poetes y pensadors y no de fets, l'experiencia dels últims quaranta anys ha demostrat tot lo contrari. En els temps de sa grandesa política no sols Alemanya ha conservat sa anterior potencia científica, sinó que aquesta li ha permès resoldre molts dels problemes que havien sorgit

83 Amadeu Maurel, "La moralitat alemanya», El Poble Català, any VII, núm. 2005 (30/8/I9IO), p. 2. 
del sí del seu gran poder polític y econòmic. Així, doncs, la Ciencia y la Pràctica dels interessos materials continúen en aquesta Alemanya, completament unides y completamentantse l'una a l'altra. ${ }^{84}$

Montoliu també es lamentava que el Kaiserreich alemany fos un destí poc atractiu pels estudiants del Regne d'Espanya. En un article titulat "Coses d'Alemanya. Estadística eloqüent», publicat en El Poble Català, el 4 de juliol de I9ıo, el filòleg tarragoní analitzava unes estadístiques que deien que entre el curs 1905-1906 i el curs 1909I9Io s'havia passat de vint estudiants espanyols a Alemanya a vint-inou. Montoliu considerava que aquestes eren unes xifres massa baixes, perquè des de l'Estat espanyol es desaprofitava una oportunitat per millorar el sistema acadèmic hispànic. ${ }^{85}$

Una de les coses que més cridaren l'atenció a Montoliu del sistema universitari del Kaiserreich foren les associacions d'estudiants. Les associacions d'estudiants eren tota una institució en terres germàniques des de feia segles, amb els seves tradicions i costums. Fins i tot a principis del segle $\mathrm{xx}$, en el món universitari alemany encara existia la cultura del duel a sabre, una especialitat coneguda com a Mensur, ${ }^{86}$ un estil d'esgrima creat a les universitats germàniques pensat per evitar la mort dels duelistes. La Universitat de Halle tenia les seves pròpies associacions de Mensur, les quals gaudien de fort prestigi. ${ }^{87}$ Montoliu, en un article titulat "Coses d'Alemanya. Els estudiants y la política», publicat a El Poble Català el is de novembre de I9IO, creia que aquestes tradicions estudiantils s'extingirien per ser

84 Manuel de Montoliu, «Coses d'Alemanya. El centenari de La universitat de Berlín», El Poble Català, any VII, núm. 2057 (22/Io/I9Io), p. I.

85 Manuel de Montoliu, "Coses d'Alemanya. Estadística eloqüent", El Poble Català, any VII, núm. I948 (4/7/I9Io), p. I.

86 La traducció en català seria "dimensió».

87 Kevin Mcaleer, Dueling: The Cult of Honor in Fin-de-Siècle Germany, Princenton, Princeton University Press, 1994, pp. I19-159. 
anacròniques amb els canvis polítics i socials que estava vivint l'Europa d'aquell període:

Però aquest romanticisme tradicional dels estudiants alemanys ab les llurs bandes y uniformes, ab els llurs duels y les llurs orgies de cervesa, està sofrint una fonda y lenta crisi que acabarà per ferlo desaparèixer. Es impossible de sostenir en els nostres temps de lluita y de responsabilitat individual aquesta concepció que d'uns ciutadans, ja ab tota la conciencia dels devers de ciutadania, ne fa una casta apart que's tanca en un paradís artificial isolat en mitg de les lluites socials del món modern. ${ }^{88}$

\section{Retorn a Barcelona (1911-1961)}

Montoliu tornà a Barcelona poc després d'acabar el cinquè semestre a Halle, el març de l'any I9II i treballà per a la Diputació de Barcelona. Quan esdevingué secretari redactor de les Oficines Lexicogràfiques de la Secció Filològica de l'Institut d'Estudis Catalans collaborà amb Pompeu Fabra en l'edició del Diccionari Agulló. ${ }^{89}$ L'any I9I2, Montoliu publicà la seva primera obra important Estudis de Literatura catalana, una recopilació d'articles sobre literatura escrits entre els anys I898 i I9I2. El periodista mallorquí Miquel dels Sants Oliver i Tolrà, director del diari liberal La Vanguardia entre I90I i I920, escrigué el pròleg d'aquest llibre, i considerava que Montoliu "palpita la promesa de algo próximo y de gran empuje para nuestra cultura». $9^{\circ}$ Gràcies al contacte amb Miquel dels Sants Oliver, Mon-

88 Manuel de Montoliu, "Coses d'Alemanya. Els estudiants y la política», El Poble Català, any VII, núm. 208I (I5/II/I9IO), p. I.

89 Joan Julià Muné, Pere Barnils..., cit., p. 38.

90 Adolfo Sotelo VÁzquez, «Montoliu y la historia literaria», Cultura/s. Revista Cultural de la Vanguardia, I7/10/2015, p. I4. 
toliu deixà de colllaborar amb El Poble Català un cop tornat de Halle i entre l'octubre del I9II i el maig del 1916 treballà per a La Vanguardia on publicà un total de 34 articles sota el títol de «Letras catalanas». ${ }^{91}$

Però Montoliu no només colllaborà amb La Vanguardia, també ho va fer amb el diari republicà El Diluvio entre el I9I2 i els primers mesos de la Primera Guerra Mundial. El filòleg tarragoní continuà fent la mateixa tasca que havia realitzat per a El Poble Català durant el temps que va estar pensionat en el Kaiserreich alemany, aquesta vegada sota el títol «Desde Alemania». Montoliu treballà per El Diluvio per una qüestió econòmica i no ideològica, com es pot veure en la seva correspondència. Fins i tot abans d'anar a Halle, Montoliu havia intentat treballar per al diari La Veu de Catalunya, el qual estava dirigit per Prat de la Riba, fet que ho demostren les diverses cartes que envià el filòleg tarragoní al dirigent de la Lliga a partir del 1907, en les quals demanava poder colllaborar en el principal mitjà de comunicació del catalanisme conservador. A més, durant els primers anys del segle $\mathrm{xx}$, el filòleg tarragoní passà de ser el «jove revolucionari» de finals del segle xix descrit per Josep Maria de Sagarra a postures ideològiques molt més conservadores. Mesos després d'haver començat a treballar per a El Diluvio, Montoliu envià una carta el dia 9 d'octubre de I9I2 a Prat de la Riba, i hi explicava quines eren les seves condicions laborals en el diari republicà a banda d'exposar dues constants que l'havien marcat al llarg dels anys: la seva dretanització ideològica i la voluntat de poder treballar a La Veu de Catalunya:

Distingit Sr. i amic: Me permeto avui molestar la seva atenció per oferir a V.[ostè] la meva colllaboració a la "Veu de Catalunya». El motiu que m’empeny á fer semblant proposició es el de trovarme avui formalment el compromís en posar la meva firma en unes Cróniques alemanes que fins ara escrivia per «El Diluvio» ab la meva sola inicial. Com

9I Ídem, p. I4.

Cercles. Revista d'Història Cultural, 24 (2021), 79-122. ISSN: 1139-0158. e-ISSN: 1699-7468. DOI: 10.1344/cercles2021.24.1003. 
sia que l'evolució que sofert ca les meves idees aquests derrers anys m'allunya cada dia mes del camp de les esquerres, i sentintme de dia en dia ab una creixenta incomoditat espiritual dintre dels circols d'aquest camp que encara no he pogut abandonar, me decideixo avui, confiat en la seva amistat de sortir d'un círcol d'idees polítiques, socials i religioses que repugnen á les seves, i evitarme l'estampar ara el meu nom en un diari de significació tan concreta com «El Diluvio», lo qual allargaria considerablement els meus esforços per sortir d'una vegada de tot lo que sigui esquerra, república i democracia. La quantitat que en el damunt dit diari me donen fer les meves cróniques es la de ioo ptes mensuals (4 articles al mes). Ara V. [ostè] veji, si es possible la meva collaboració a “"La Veu» per la mateixa quantitat, que es lo que necessitaria. Y en cas de ser possible, V.[ostè] mateix ja coneix prou bé el fort i el fluix de la meva illustració per saber que podria fer pel seu diari. Accepti avui la meva bona disposició i el meu viu desij de colaborar en la publicació que surt baix la seva illustrada direcció. Espero que’m fará saber aviat la seva resolució i que en tot cas guardará absoluta reserva sobre el contingut d'aquesta lletra, lo qual prego à V.[ostè] insistenment. ${ }^{92}$

Manuel de Montoliu no pogué treballar per a La Veu de Catalunya fins a l'any $1923 . .^{93}$

A part de la seva feina a l'IEC i la colllaboració que tingué amb Pompeu Fabra, Montoliu va desenvolupar una extensa carrera acadèmica un cop tornat de Halle. Primer de tot, entre les dècades de I9Io i de I930 es convertí en professor de llengua castellana per la Universitat de Barcelona. A més, el filòleg tarragoní tingué una carrera acadèmica fora de l'àmbit espanyol: l'any 1920 va ser lector de català i castellà a la Universitat d'Hamburg i l'any 1925 dirigí l'Instituto de Filología de la Universitat de Buenos Aires. A causa de l'es-

92 Arxiu Nacional de Catalunya. Llegat Puig i Cadafalch: ANCI-I37-T-2797.

93 Adolfo Sotelo VÁzquez, «Montoliu y la historia literaria», Cultura/s. Revista Cultural de la Vanguardia, I7/Io/2015, p. I4. 
clat de la Guerra Civil Espanyola, l'any 1936 Montoliu s'exilià a França. A partir del 1937 començà a treballar per l'oficina de premsa de la Itàlia feixista, un dels estats vitals en el suport militar al bàndol rebel de la Guerra Civil. Un cop acabat el conflicte bèllic, Montoliu tornà a Catalunya. L'any 1943 morí la seva esposa, la violinista Júlia Vidal. Aquest fet va provocar que entre els anys 1943 i 1945 ingressés a la vida monacal al Monestir de Poblet. A partir de l'any 1945, fou elegit assessor cultural de la Diputació de Tarragona i va ser escollit vicepresident del Patronat de Poblet i vicepresident director de l'Instituto de Estudios Tarraconenses Ramón Berenguer IV. Morí a Barcelona el dia I8 de maig de l'any I96I a l'edat de 84 anys. ${ }^{94}$

\section{Conclusions}

Bona part dels escrits historiogràfics que han tractat el tema dels que viatjaren a l'Imperi alemany entre 1890 i I9I4, ho han analitzat principalment com un esdeveniment purament biogràfic. La majoria d'escrits acadèmics es concentren bàsicament en les experiències personals d'aquests individus i poques vegades hi ha un aprofundiment extensiu del context de l'època, el qual podria ajudar a entendre el que suposà el viatge d'aquests catalans a l'Alemanya guillermina en el context de dinamització cultural del Principat durant aquest període. Tot i això, hi ha excepcions, com seria la biografia de Pere Barnils feta per Julià Muné, on s'explica el context cultural de la filologia catalana de principis del segle $\mathrm{xx}^{95}$

No tots els treballs han tractat aquest tema des d'una perspectiva biogràfica. Per exemple, l'estada de Vidal Guardiola a l'Imperi ale-

94 Àlex Broch (ed.), Diccionari de la literatura catalana, Barcelona, Enciclopèdia Catalana, 2008, p. 656.

95 Joan Julì̀ Muné, Pere Barnils..., pp. I8-35.

Cercles. Revista d'Història Cultural, 24 (2021), 79-122. ISSN: 1139-0158. e-ISSN: 1699-7468. DOI: 10.1344/cercles2021.24.1003. 
many està tractada historiogràficament com un element per entendre el noucentisme econòmic de la dècada de I900. A la tesi d'Antoni Guirao, es contraposaren els articles de Manuel de Montoliu amb els de Vidal Guardiola per analitzar dos punts de vista diferents de dos pensionats que estudiaren a l'Alemanya guillermina. ${ }^{96}$ També s'ha d'esmentar l'estudi de Mercè Vidal sobre el viatge de Josep Maria Folch i Torres per Europa entre els anys I9I3 i I9I4, on mencionà la importància que tenien aquests pensionats per part de l'administració Prat de la Riba per millorar el sistema cultural català. ${ }^{97}$ I tampoc es poden deixar de banda els múltiples escrits d'Albert Balcells sobre el dinamisme cultural del món acadèmic català del primer terç del segle $\mathrm{xx}$, en què menciona la importància dels pensionats en la modernització de les estructures de poder i intel.lectuals del Principat. Però cal destacar un petit llibre escrit per Fèlix Villagrassa, titulat Mancomunitat i ciència: La modernització de la cultura catalana, on hi ha un important recull (amb petita nota biogràfica) dels diferents pensionats catalans que estudiaren fora del Regne d'Espanya beneficiats per les diferents administracions catalanes i espanyoles, entre els quals hi ha els noms d'aquells individus que viatjaren a l'Imperi alemany abans del I9I4. ${ }^{98}$

Les opinions dels personatges que viatjaren al Segon Reich entre I890 i I9I4 són imprescindibles per entendre bé la visió de l'Imperi alemany per part de la cultura catalana. Aquests intel.lectuals són importants perquè estigueren físicament a l'Alemanya guillermina i podien fer descripcions a partir de les seves experiències sense la necessitat d'intermediaris. Això és un punt destacat, ja que cal recordar que la major part de la informació del Segon Reich que arribava a

96 Antoni Guirao, «La Cataluña»..., pp. 579-597.

97 Mercè Vidal JansÀ, «Entorn del recull epistolar I9II-I9I6», dins Mercè VidaL JaNSÀ, Enric Prat de la Riba i les arts: recull epistolar I9II-I9I6, Barcelona, Cubert, 20I4, p. 64. 98 Fèlix Villagrasa Hernández, Mancomunitat $i$ ciència..., pp. 2I-28. 
Catalunya era filtrada per la República Francesa, la qual era rival directe de l'Imperi alemany pel domini de l'Europa Occidental. Tot i això, cal entendre que les percepcions que tingueren aquests individus sobre el Segon Reich eren subjectives i estaven lligades a les pròpies ideologies i a l'experiència viscuda personalment. A més, algunes d'aquestes persones, com per exemple alguns dels pensionats, només viatjaren a una o dues ciutats de l'Alemanya guillermina i, per tant, moltes vegades les vivències i observacions que podien tenir d'una localitat concreta ho extrapolaven a tot l'Imperi alemany.

Una de les coses que s'ha d'entendre d'aquests individus que viatjaren a l'Alemanya en aquella època és que no només foren importants perquè hi viatgessin. Aquests intel.lectuals eren destacats en els seus camps laborals i acadèmics. Això és un punt importantíssim, perquè molts d'ells, sobretot els pensionats que s'enviaren a l'Imperi alemany partir dels anys 1907-I908, ocuparen càrrecs de vital importància durant les dècades següents, des de posicions administratives a la Diputació de Barcelona i la Mancomunitat a partir del I9I4, com el cas de Rubió Balaguer que fou el primer president de la Biblioteca de Catalunya del I9I4 al 1939, ${ }^{99}$ fins a importants posicions acadèmiques, com el cas de Pere Bosch i Gimpera, que gràcies als seus estudis a Berlín i a Munic es convertí en un dels primers prehistoriadors acadèmics del Regne d'Espanya i el primer rector de la Universitat Autònoma de Barcelona entre els anys I933 i I939. ${ }^{100}$

Montoliu fou un exemple dels estudiants que es beneficiaren de la política d'enviar estudiants a estudiar a l'Alemanya guillermina per part de les diferents administracions públiques a partir de la segona meitat de la dècada de I900. El cas dels tres pensionats a Halle fou un exemple de la gran participació de l'administració Prat de la

99 Albert Balcells, Enric Pujol, Jordi Sabater, La Mancomunitat de Catalunya..., pp. $453-457$.

ioo Pere Bosch Gimpera, Memòries, Edicions 62, Barcelona, I980, p. 74. 
Riba a becar estudiants catalans a diferents destins fora de la Península Ibèrica. Les experiències de Montoliu a Halle demostren algunes de les dificultats logístiques i econòmiques que visqueren tant les administracions com els pensionats que anaren a l'estranger. A més, la disputa i el trencament entre Schädel i els tres pensionats catalans demostra que les estades acadèmiques dels becats fora del Regne d'Espanya no sempre foren reeixides. Tot i això, l'experiència de Montoliu a l'Imperi alemany (com la d'altres pensionats a l'estranger) és destacada per dos grans motius que detallem tot seguit.

Primer de tot, haver conegut una realitat universitària diferent. A partir dels escrits de Montoliu, des de les cartes personals fins a les cròniques periodístiques, l'experiència va fer que membres destacats del món intel.lectual i l'opinió pública catalans poguessin accedir al coneixement en primera persona de com funcionava un sistema acadèmic diferent, i fins i tot considerat més eficient, al del Regne d'Espanya com era el cas de l'Alemanya guillermina.

Segon, l'experiència acadèmica del filòleg tarragoní a l'Imperi alemany. L'aprenentatge adquirit a la Universitat de Halle li va permetre, un cop retornat a Catalunya, adquirir càrrecs tant en entitats com en administracions de la Diputació de Barcelona i de la posterior Mancomunitat, com molts altres estudiants que estudiaren becats fora del Regne d'Espanya. Per exemple, Manuel de Montoliu, com ja s'ha dit, es convertí en secretari redactor a les Oficines Lexicogràfiques de la Secció Filològica de l'Institut d'Estudis Catalans. ${ }^{\text {IOI }}$

ior Albert Balcells, Enric Pujol, Jordi Sabater, La Mancomunitat de Catalunya..., pp. 44I-457. els autors, citats a la referència que apareix a l'inici del document. 